\title{
Effects of a 4-year intervention on hand hygiene compliance and incidence of healthcare associated infections: a longitudinal study
}

\author{
Chengyi Han ${ }^{1} \cdot$ Qing Song ${ }^{1} \cdot$ Xin Meng ${ }^{1} \cdot$ Ying $\mathrm{Lv}^{1} \cdot$ Dongsheng $\mathrm{Hu}^{2} \cdot$ Xuesong Jiang $^{1}{ }^{\mathbb{D}} \cdot$ Liang Sun $^{2}$
}

Received: 29 January 2021 / Accepted: 6 May 2021 / Published online: 14 May 2021

○) Springer-Verlag GmbH Germany, part of Springer Nature 2021

\begin{abstract}
Purpose Studies have demonstrated improvements in hand hygiene (HH) compliance through interventions, noting the negative association of $\mathrm{HH}$ and healthcare associated infections (HAIs), but how to sustain long-term improvement is still unknown in the Chinese population. This study sought to determine the extent of change in HH compliance after multimodal $\mathrm{HH}$ interventions, and to evaluate the relationship between that change and HAI incidence.

Methods We conducted a longitudinal study in a general teaching hospital in China from 2017 to 2020. Trained investigators observed HH practices based on the World Health Organization's 5 moments for HH. We identified the incidence of HAIs using semi-automated constant surveillance software. We used the Cochran-Mantel-Haenszel test to assess the secular trend of HH compliance and HAIs. The Spearman correlation coefficient $\left(r_{\mathrm{s}}\right)$ was used to evaluate the relationship between the incidence of HAIs and compliance with HH.

Results The study made 480,943 observations, where HH was occurring between 2017 and 2020. HH compliance increased from 68.90 to $91.76 \%$ during that period $\left(P_{\text {trend }}<0.01\right)$, while the incidence of HAIs decreased from 1.10 to $0.91 \%$. Compliance also increased for each moment type and for each healthcare worker $\left(P_{\text {trend }}<0.01\right)$. Lower HH compliance was observed in before-patient contact and after contact with patient surroundings, and among interns and cleaners. We also observed a weak but statistically significant negative correlation between the monthly HH compliance and incidence of HAIs $\left(r_{\mathrm{s}}=-0.27 ; P=0.037\right)$.

Conclusions The multimodal $\mathrm{HH}$ implementation delivered sustained improvement in $\mathrm{HH}$ compliance, and this change was associated with a decline in the incidence of HAIs.
\end{abstract}

Keywords Healthcare associated infection $\cdot$ Hand hygiene $\cdot$ Compliance $\cdot$ Incidence

\section{Introduction}

Healthcare associated infections (HAIs) are a serious public health problem experienced around the world, but often preventable, giving rise to extra treatment costs, complications, and mortality [1-3]. Improvement in hand hygiene (HH) compliance among healthcare workers is the simplest, most effective, and most cost-effective measure for reducing

Xuesong Jiang

jxswzj@126.com

$\triangle$ Liang Sun

zzusunl@163.com

1 The First Affiliated Hospital of Henan University of CM, 19 Renmin Road, Jinshui District, Zhengzhou 450003, China

2 School of Public Health, Zhengzhou University, 100 Kexue Avenue, Gaoxin District, Zhengzhou 450001, China
HAIs in hospitals [4, 5]. Several longitudinal studies found a negative association of $\mathrm{HH}$ and HAIs, but they were not based on the Chinese population [6-8]. Moreover, while studies have demonstrated increases in $\mathrm{HH}$ compliance through interventions, how to sustain long-term improvement is unknown [9-11]. Despite availability of promising new electronic methods for automatically monitoring $\mathrm{HH}$ activity, these technologies have their limitations in realworld settings [12]. Direct observation is still an important method of measuring HH performance, as outlined in the World Health Organization's (WHO) guidelines [12, 13]. We, therefore, conducted a 4-year longitudinal study in the Chinese population to explore the effects of improvement in directly observed $\mathrm{HH}$ practices and the relationship between increased $\mathrm{HH}$ compliance and decreased HAI incidence. 


\section{Methods}

\section{Study design}

The longitudinal study was conducted in the first affiliated hospital of Henan University of CM, a provincial general teaching hospital with about 2600 beds, 3100 healthcare workers, 55 inpatient wards, and 10 days per year of stay in China, between January 2017 and September 2020. The study population included all the healthcare workers tending to inpatients in the hospital. The infection control team implemented multimodal interventions to improve $\mathrm{HH}$ compliance among healthcare workers. We conducted regular training twice a year about the practice and importance of $\mathrm{HH}$ and meridian in the hands for all the healthcare workers (including new staff and students). We also offered irregular activities including general training, game shows, or electronic videos. Observers were required to give immediate feedback to the observed healthcare workers about their $\mathrm{HH}$ performance after the observation. Overall $\mathrm{HH}$ compliance was published monthly and quarterly in department meetings and on the infection control supervision platform, respectively. Over the years, the hospital has provided various reminders, products, and facilities for $\mathrm{HH}$ (in the supplement) to improve compliance in the hospital.

\section{HH in the hospital}

We recruited $78 \mathrm{HH}$ observers from veteran nurses, doctors, and medical technicians for the study. Indispensable knowledge (such as how to perform $\mathrm{HH}$, fill out the questionnaire, and submit data) was transmitted to them in the technical training to ensure satisfactory completion of the study. A paper questionnaire was used to collect data on $\mathrm{HH}$ practices by trained observers in accordance with the WHO's 5 moments for $\mathrm{HH}$ (before touching a patient, before a clean/aseptic procedure, after body fluid exposure risk, after touching a patient, and after touching patient surroundings). Observers performed $\mathrm{HH}$ surveys irregularly, at least once each week. All interviews were performed and checked by dedicated study staff. Observers rechecked the HH information before submitting it to ensure good data quality. The data were submitted by each trained observer to the department of infection control once per month (before the 5th of the following month).

\section{HAIs}

HAI cases in the study were infected inpatients in hospital. We determined the incidence of HAIs among inpatients by analyzing the hospital's records. The Xinglin Real Time
Nosocomial Infection Surveillance Software of Hangzhou Xinglin Science Technology Limited Company was used to follow the incidence of HAIs among inpatients; the software is linked to all the electronic databases in the hospital. When a patient uses antibiotics for more than 3 days, or has fever, or abnormal results from biochemical, microbiological and imaging tests, the software automatically generates a window requiring doctors to provide information. Doctors are initially required to determine whether the patient represented a HAI case or not according to the pilot version of the diagnostic criteria for HAI proposed by the Health Ministry of China [14]. Two infection-control workers then recheck the patient's medical records and ultimately confirm the diagnosis based on the aforementioned diagnostic criteria.

\section{Statistical analyses}

HH compliance was calculated as the number of observations, where the necessary $\mathrm{HH}$ was practiced divided by the total number of observations, where $\mathrm{HH}$ was needed. We also calculated the monthly and annual incidence of HAIs over the study period as the number of HAIs divided by the total number of inpatients. The Cochran-Mantel-Haenszel test was used to assess the secular trend of $\mathrm{HH}$ compliance and HAIs. We also assessed the correlation of the HH compliance and incidence of HAIs using the Spearman correlation coefficient $\left(r_{\mathrm{s}}\right)$ to control for any possible time-related confounding. All analyses involved use of SAS 9.1 (SAS Inst., Cary, NC).

\section{Results}

\section{Basic characteristics}

The study made 480,943 observations, where $\mathrm{HH}$ was occurring between 2017 and 2020. The HH compliance increased from $68.90 \%$ in 2017 to $91.76 \%$ in 2020 and the incidence of HAIs decreased from 1.10 to $0.91 \%\left(P_{\text {trend }}<0.01\right.$; Table 1$)$. Detailed data are in Table $\mathrm{S} 1$ in the supplement.

\section{Changes in monthly HH compliance}

The HH compliance increased from $64.78 \%$ in January of 2017 to $90.51 \%$ in September of 2020 ( $P<0.01$; Fig. 1). Between January 2017 and September 2020, the HH compliance of 5 moments demonstrated an upward trend, while $\mathrm{HH}$ compliance in after body fluid exposure risk and before a clean/aseptic procedure was higher than before patient contact and after contact with patient surroundings $\left(P_{\text {trend }}<0.01\right.$; Fig. 2$)$. The improvement in HH compliance was observed among all healthcare worker categories, with higher compliance among nurses and medical technicians 
Table 1 Hand hygiene observations and compliance, and healthcare associated infection, China, 2017-2020

\begin{tabular}{lllllll}
\hline Year & No. of observations & $\begin{array}{l}\text { No. of observations, } \\
\text { where compliance } \\
\text { with hand hygiene was } \\
\text { recorded }\end{array}$ & $\begin{array}{l}\text { Hand hygiene com- } \\
\text { pliance, \% (95\% CI) }\end{array}$ & $\begin{array}{l}\text { No. of inpatients } \\
\text { No. of healthcare }\end{array}$ & $\begin{array}{l}\text { Incidence of healthcare } \\
\text { associated infec- } \\
\text { tions } \\
\text { associated infection, \% } \\
(95 \% \text { CI) }\end{array}$ \\
\hline 2017 & 138,729 & 95,586 & $68.90(68.66-69.14)$ & 91,261 & 1006 & $1.10(1.10-1.17)$ \\
2018 & 119,967 & 97,735 & $81.7(81.25-81.69)$ & 113,144 & 1037 & $0.92(0.81-0.97)$ \\
2019 & 123,335 & 106,652 & $86.47(86.28-86.64)$ & 127,907 & 1172 & $0.92(0.86-0.97)$ \\
2020 & 98,912 & 90,764 & $91.76(91.59-91.93$ & 71,481 & 648 & $0.91(0.84-0.98)$ \\
Total & 480,943 & 390,737 & $81.24(81.13-81.35)$ & 403,793 & 3863 & $0.96(0.93-0.99)$ \\
\hline
\end{tabular}

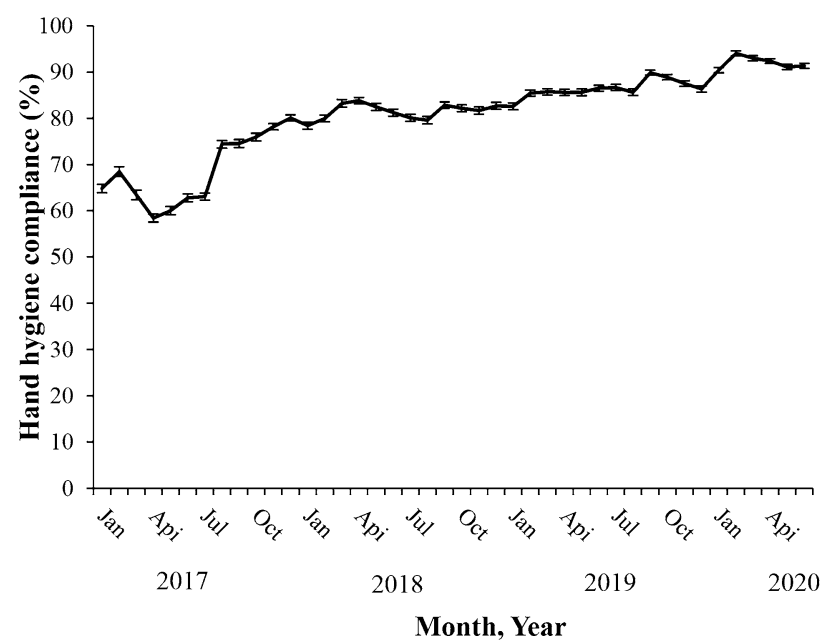

Fig. 1 Changes in overall hand hygiene compliance by month

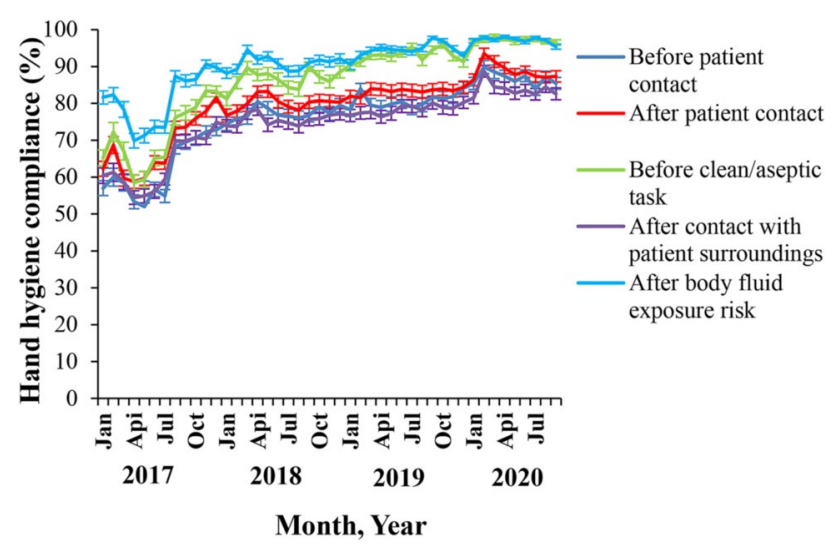

Fig. 2 Changes in hand hygiene compliance for each of the WHO's 5 moments by month

than among interns and cleaners $\left(P_{\text {trend }}<0.01 ;\right.$ Fig. 3$)$. We observed an upward trend in HH compliance among unit types $\left(P_{\text {trend }}<0.01\right.$; Fig. 4$)$. Detailed data are in Tables $\mathrm{S} 1-\mathrm{S} 4$ in the supplement.

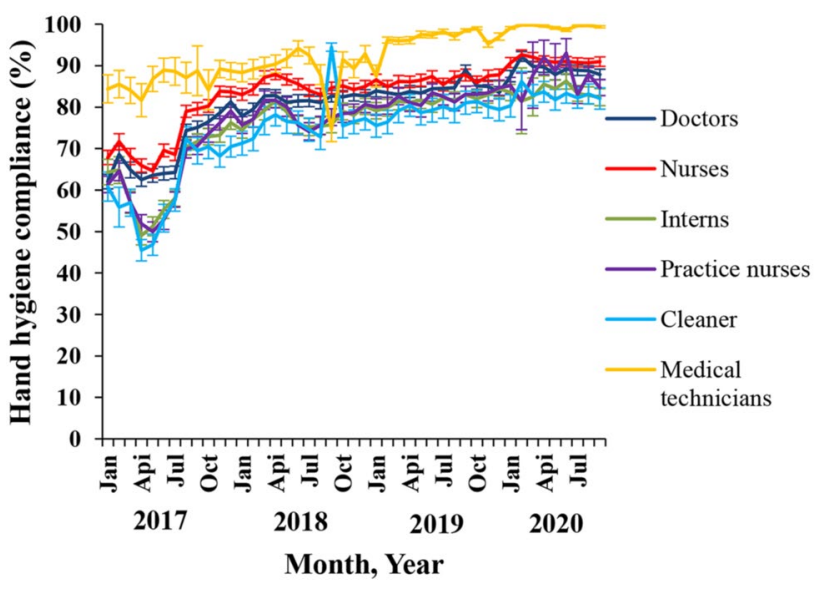

Fig. 3 Changes in hand hygiene compliance for each of the six key healthcare worker groups by month

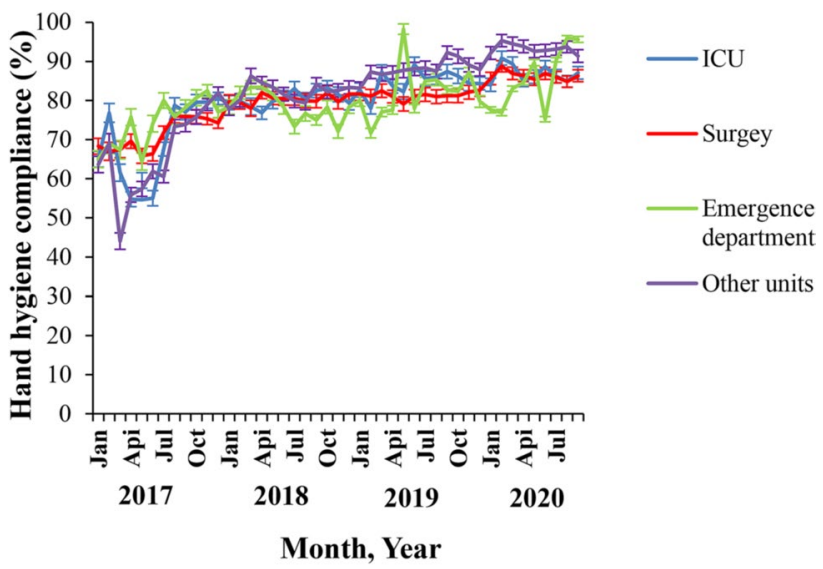

Fig. 4 Changes in hand hygiene compliance for each unit type by month

\section{Correlation between monthly incidence of $\mathrm{HH}$ compliance and HAls}

Figure 5 shows a weak but statistically significant negative correlation between monthly $\mathrm{HH}$ compliance and incidence 


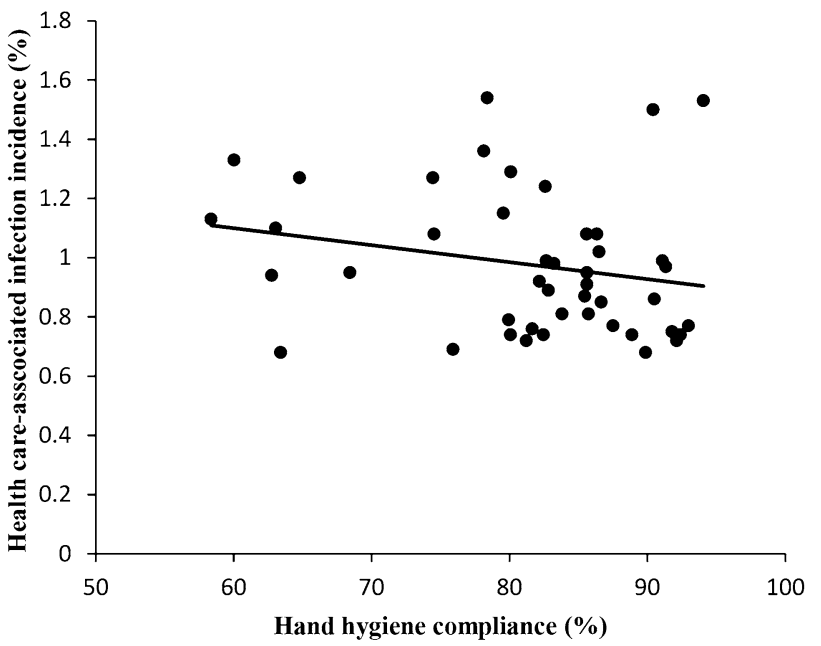

Fig. 5 Correlation between monthly incidence of health care associated infections and hand hygiene compliance

of HAIs $\left(r_{\mathrm{s}}=-0.27 ; P=0.037\right)$. Detailed data and HAI data by infection sites are in Tables S1 and S5 in the supplement.

\section{Discussion}

Our results show that the upward trend in HH compliance was sustained, and that this change was negatively associated with the incidence of HAIs after 4 years of multimodal $\mathrm{HH}$ intervention. Lower HH compliance was observed in before-patient contact and after contact with patient surroundings, and among interns and cleaners.

Australian national studies [15] that included public and private hospitals demonstrated that $\mathrm{HH}$ initiatives were associated with a significant increment in $\mathrm{HH}$ adherence and a decline in the incidence of healthcare-associated staphylococcus aureus bacteraemia after 8 years of infection control practices, consonant with our study. A prospective interventional study also demonstrated a similar improvement in HH compliance and a decrease in HAIs in ICU patients after implementation of an infection-control program, while a decline in overall incidence of HAIs was not observed [16]. Improvement in $\mathrm{HH}$ compliance among hospital healthcare workers may profit from comprehensive intervention and constant feedback [17].

We found an increase in $\mathrm{HH}$ compliance by 5 moments across all healthcare workers and unit types with implementation of multimodal $\mathrm{HH}$ interventions, similar to findings of previous reports $[15,18,19]$. Comparing other moments and healthcare workers, $\mathrm{HH}$ compliance was generally lower for before touching a patient and after contact with patient surroundings, while compliance was lower among interns and cleaners. Previous reports $[15,18,20,21]$ showed a decline of HAIs after improvement in $\mathrm{HH}$ compliance (from
66.2 to $95.9 \%$ ) after long-term $\mathrm{HH}$ implementation. Unfortunately, $\mathrm{HH}$ adherence is generally suboptimal worldwide [22], including in China, as we have shown in this study. These findings indicate that the incidence of HAIs might further reduce if monthly $\mathrm{HH}$ compliance continues to trend upwards, supporting the WHO's recommendations about improved $\mathrm{HH}$ practices [6].

Our study's strength lies in the fact that direct observations of HH compliance and semi-automated HAI surveillance were recorded regularly (on a monthly basis) in a real-life setting. Compared with new electronic methods of tracking $\mathrm{HH}$ practice, direct observation is still considered gold standard [6]. The high HH compliance in 2020 might be associated with the outbreak of coronavirus disease 2019 (COVID-19) in December 2019. This study used direct observation to collect HH data, which also might imply observational bias. The combination of direct observation and electronic methods might prove valuable in collecting good HH data. The introduction of semi-automated electronic surveillance in this study made it easier to identify HAIs and reduced the time taken to link patients with infection-control workers [23]. We did not obtain information on possible changes in other factors associated with $\mathrm{HH}$ compliance and HAIs over time, however, which may have resulted in over- or underestimation of the effects of intervention. Although HH compliance and HAIs might be inconsistent between departments, we did not analyze them by departments because of limited data. We could not perform analysis by infection site for the same reason. This study used the number of HAIs per 100 patients measure of HAI incidence according to the norm of nosocomial infection surveillance proposed by the Health Ministry of China, because we did not collect patient day data, although most studies published in English use the number of HAIs per 1000 patient days to measure HAI incidence; thus, we could not compare our HAI incidence with studies that used the number of HAIs per 1000 patient days. In addition, the observation period may have been too short to evaluate the decreased incidence of HAIs following HH implementation. These issues highlight the necessity of further studies to clarify the relationship between HH compliance and HAIs and to evaluate the specific effect of $\mathrm{HH}$ interventions on the incidence of HAIs.

\section{Conclusion}

This study found that multimodal $\mathrm{HH}$ implementation measures delivered sustained improvement in $\mathrm{HH}$ compliance, and that this improvement was associated with a decline in the incidence of HAIs.

Supplementary Information The online version contains supplementary material available at https://doi.org/10.1007/s15010-021-01626-5. 
Author contributions All authors contributed to data analysis, drafting, or revising the article, gave final approval of the version to be published, and agreed to be accountable for all aspects of the work.

Funding This work was supported by the Culture and Management Foundation of Traditional Chinese Medicine of Henan [Grant number: TCM2019012].

\section{Declarations}

Conflict of interest The authors declare that they have no conflict of interest.

Ethical approval The present study has been approved by the appropriate ethics committee (2019HL-160) and has, therefore, been conducted in accordance with the ethical standards laid down in the 1964 Declaration of Helsinki and its later amendments.

Informed consent Due to nature of the study, the Ethics Committee determined that no patient consent was required.

\section{References}

1. Magill SS, O'Leary E, Janelle SJ, Thompson DL, Dumyati G, Nadle J, et al. Changes in prevalence of health care-associated infections in U.S. hospitals. N Engl J Med. 2018;379:1732-44. https://doi.org/10.1056/NEJMoa1801550.

2. Graves N, Weinhold D, Tong E, Birrell F, Doidge S, Ramritu P, et al. Effect of healthcare-acquired infection on length of hospital stay and cost. Infect Control Hosp Epidemiol. 2007;28:280-92. https://doi.org/10.1086/512642.

3. Cassini A, Plachouras D, Eckmanns T, Abu Sin M, Blank H-P, Ducomble T, et al. Burden of six healthcare-associated infections on European population health: estimating incidence-based disability-adjusted life years through a population prevalence-based modelling study. PLoS Med. 2016;13:e1002150. https://doi.org/ 10.1371/journal.pmed.1002150.

4. Burke JP. Infection control-a problem for patient safety. N Engl J Med. 2003;348:651-6. https://doi.org/10.1056/NEJMhpr020557.

5. Mathai E, Allegranzi B, Kilpatrick C, Bagheri Nejad S, Graafmans W, Pittet D. Promoting hand hygiene in healthcare through national/subnational campaigns. J Hosp Infect. 2011;77:294-8. https://doi.org/10.1016/j.jhin.2010.10.012.

6. World Health Organization. WHO guidelines on hand hygiene in health care: first global patient safety challenge clean care is safer care. 2009.

7. Grayson ML, Russo PL, Cruickshank M, Bear JL, Gee CA, Hughes CF, et al. Outcomes from the first 2 years of the Australian National Hand Hygiene Initiative. Med J Aust. 2011;195:615-9. https://doi.org/10.5694/mja11.10747.

8. Kirkland KB, Homa KA, Lasky RA, Ptak JA, Taylor EA, Splaine ME. Impact of a hospital-wide hand hygiene initiative on healthcare-associated infections: results of an interrupted time series. BMJ Qual Saf. 2012;21:1019-26. https://doi.org/10.1136/ bmjqs-2012-000800.

9. Gould DJ, Moralejo D, Drey N, Chudleigh JH, Taljaard M. Interventions to improve hand hygiene compliance in patient care. Cochrane Database Syst Rev. 2017;9:Cd005186. https://doi.org/ 10.1002/14651858.CD005186.pub4.

10. Gould D, Moralejo D, Chudleigh J, Drey N. The Australian National Hand Hygiene Initiative: framework for future research.
Lancet Infect Dis. 2018;18:1171-2. https://doi.org/10.1016/ s1473-3099(18)30598-x.

11. Talbot TR, Johnson JG, Fergus C, Domenico JH, Schaffner W, Daniels TL, et al. Sustained improvement in hand hygiene adherence: utilizing shared accountability and financial incentives. Infect Control Hosp Epidemiol. 2013;34:1129-36. https://doi. org/10.1086/673445.

12. Boyce JM. Electronic monitoring in combination with direct observation as a means to significantly improve hand hygiene compliance. Am J Infect Control. 2017;45:528-35. https://doi. org/10.1016/j.ajic.2016.11.029.

13. Stewardson A, Sax H, Longet-Di Pietro S, Pittet D. Impact of observation and analysis methodology when reporting hand hygiene data. J Hosp Infect. 2011;77:358-9. https://doi.org/10. 1016/j.jhin.2010.12.008.

14. Health Ministry of China. The pilot version of the diagnosis criteria for nosocomial infection. J Chin Med 2001;81:314-20 (In Chinese)

15. Grayson ML, Stewardson AJ, Russo PL, Ryan KE, Olsen KL, Havers SM, et al. Effects of the Australian National Hand Hygiene Initiative after 8 years on infection control practices, health-care worker education, and clinical outcomes: a longitudinal study. Lancet Infect Dis. 2018;18:1269-77. https://doi.org/10.1016/ s1473-3099(18)30491-2.

16. Hagel S, Ludewig K, Pletz MW, Frosinski J, Moeser A, Wolkewitz M, et al. Effectiveness of a hospital-wide infection control programme on the incidence of healthcare-associated infections and associated severe sepsis and septic shock: a prospective interventional study. Clin Microbiol Infect. 2019;25:462-8. https://doi. org/10.1016/j.cmi.2018.07.010.

17. Stewardson AJ, Sax H, Gayet-Ageron A, Touveneau S, Longtin Y, Zingg W, et al. Enhanced performance feedback and patient participation to improve hand hygiene compliance of health-care workers in the setting of established multimodal promotion: a single-centre, cluster randomised controlled trial. Lancet Infect Dis. 2016;16:1345-55. https://doi.org/10.1016/s1473-3099(16) 30256-0.

18. Ojanperä H, Kanste OI, Syrjala H. Hand-hygiene compliance by hospital staff and incidence of health-care-associated infections, Finland. Bull World Health Organ. 2020;98:475-83. https://doi. org/10.2471/blt.19.247494.

19. Sakihama T, Kayauchi N, Kamiya T, Saint S, Fowler KE, Ratz D, et al. Assessing sustainability of hand hygiene adherence 5 years after a contest-based intervention in 3 Japanese hospitals. Am J Infect Control. 2020;48:77-81. https://doi.org/10.1016/j.ajic. 2019.06.017.

20. Pittet D, Hugonnet S, Harbarth S, Mourouga P, Sauvan V, Touveneau $S$, et al. Effectiveness of a hospital-wide programme to improve compliance with hand hygiene. Infection Control Programme. Lancet (London, England). 2000;356:1307-12. https:// doi.org/10.1016/s0140-6736(00)02814-2.

21. Sickbert-Bennett EE, DiBiase LM, Willis TM, Wolak ES, Weber DJ, Rutala WA. Reduction of healthcare-associated infections by exceeding high compliance with hand hygiene practices. Emerg Infect Dis. 2016;22:1628-30. https://doi.org/10.3201/eid2209. 151440.

22. Pittet D. Hand hygiene: From research to action. J Infect Prev. 2017;18:100-2. https://doi.org/10.1177/1757177417705191.

23. Freeman R, Moore LS, García Álvarez L, Charlett A, Holmes A. Advances in electronic surveillance for healthcare-associated infections in the 21st Century: a systematic review. J Hosp Infect. 2013;84:106-19. https://doi.org/10.1016/j.jhin.2012.11.031. 